\title{
PERBANDINGAN TEKANAN DARAH SISTOLIK DAN DIASTOLIK SEBELUM DAN SESUDAH BEGADANG PADA SECURITYDI PERUMAHAN J-CITY MEDAN JOHOR
}

\author{
Siska Anggreni Lubis, ${ }^{1}$ Muhammad Amin ${ }^{2}$ \\ Universitas Islam Sumatera Utara, Jl. Sisingamangaraja, Medan \\ e-mail: Muhammadaa1209@gmail.com
}

\begin{abstract}
Blood pressure is the pressure generated by the blood against the blood vessel. Staying up late is being awake until late at night. All the human need a time for rest, a normal adult requires six to eight hours a day sleeping or resting after a day of working and doing activity. The purpose of this research was to compare the systolic and diastolic blood pressure before and after staying up on security in Perumhan J-City Medan Johor. This observational analytical research is cross sectional design in use with a sample of 43 securities with sampling methods Total Sampling. The results showed that 43 respondents who examined contained blood pressure increased by 32 (74\%) of people, who decreased as many as $8(18,6 \%)$ people, and being consistent $3(7 \%)$ of people. Paired T-test based on the obtained on the average systolic pressure before and after is 8.140. The result of this study relateds to the significance of $p=0,001$. For the average diastole before and after obtained -6.744 which also relates to the signifance of $p=0,001$.
\end{abstract}

Keyword : Blood pressure, Staying up late

\section{PENDAHULUAN}

Menurut World Health Organizatiton (WHO), satu dari tiga orang dewasa di seluruh dunia memiliki darah tinggi. Proporsi meningkat sejalan bertamabahnya usia,yaitu satu dari sepuluh orang berusia 20 -an dan 30 -an sampai lima dari sepuluh oranag berusia 50 -an. Orang dewasa di beberapa negara berpendapatan rendah di Afrika memiliki tekanan darah tinggi dengan persentase tertinggi sebesar lebih dari 40\% (WHO, 2013).

Berdasarkan hasil Riset Kesehatan Dasar (Riskesdas) tahun 2007, sebagian besar kasus tekanan darah tinggi pada masyarakat belum terdiagnosis. Di Indonesia, pada usia lebih dari atau sama dengan 18 tahun didapatkan prevalensi tekanan darah tinggi sebesar 31,7\% yang sudah tahu memiliki tekanan darah tinggi hanya $7,2 \%$ dan yang minum obat hipertensi hanya 0,4\% (Depkes RI,2012).

Terdapat tiga jenis tekanan darah, yaitu: tekanan darah normal, tekanan darah rendah (hipotensi), dan tekanan darah tinggi (hipertensi). Tekanan darah dikatakan normal apabila tekanan sistoliknya $120-140 \mathrm{mmHg}$ manakala tekanan diastoliknya $80-90 \mathrm{mmHg}$ menurut World Health Organization (WHO) sedangkan menurut National Heart, Lung, and Blood Institute (NHLBI) dan National Institute of Health (NIH) definisi tekanan darah normal adalah tekanan sistolik kurang dari $120 \mathrm{mmHg}$ dan tekanan diastolik kurang dari $80 \mathrm{mmHg}$.

Hipotensi adalah tekanan darah di bawah 90/ $60 \mathrm{mmHg}$ (National Heart, Lung and Blood Institute, 2010) dan Hipertensi menurut National Heart, Lung, and Blood Institute (NHLBI, 2010) adalah suatu keadaan apabila tekanan darahnya melebihi normal, yaitu tekanan sistoliknya 140 $\mathrm{mmHg}$ atau lebih tinggi manakala tekanan diastoliknya $90 \mathrm{mmHg}$ atau lebih tinggi. Lebih lanjut The Seventh Report Of The Joint National Committee On Prevention, Detection, Evaluation and Treatment Of High Blood Pressure (JNC 7), klasifikasi tekanan darah pada dewasa terbagi menjadi kelompok normal, prehipertensi, hipertensi derajat 1 dan hiperetensi derajat 2.

Hipertensi merupakan faktor risiko utama untuk morbiditas dan mortalitas kardiovaskular. Hipertensi memepercepat proses aterosklorosis pada arteri koroner, otak, dan ginjal, serta 
meningkatkan beban kerja jantung . Sebagai hasilnya pada pasien hipertensi adalah berisiko mengembangkan infark miokard, stroke, gagal ginjal, dan gagal jantung kongestif. Secara total, hipertensi mungkin secara langusng atau tidak langsung bertangung jawab atas $10-20 \%$ dari seluruh kematian ( Remmes, 2012 dalam Asmarita 2014).

Menurut National Heart, Lung and Blood Institut dari United States Department of Health and Human Services pada tahun 2009 meginformasikan bahwa kurang tidur atau kualitas tidur yang buruk meningkatkan risiko tekanan darah tinggi, penyakit jantung, dan kondisi medis lainnya. Sogol Jevari dari Case Western Reserve School of Medicine, Cleveland, melakukan sebuah penelitian mengenai hubungan kualitas tidur dan peningkatan tekanan darah pada remaja yang dipublikasikan pada Agustus 2008 oleh Circulation Journal. Kesimpulan dari peneitian tersebut bahwa kualitas tidur yang buruk berhubungan dengan kejadian pre hipertensi pada remaja yang sehat (asmarita, 2014).

Faktor-faktor hipertensi yaitu faktor risiko yang tidak dapat diubah dan faktor yang dapat diubah. Faktor yang tidak dapat di ubah terdiri dari genetika,umur, jenis kelamin, sedangkan faktor yang dapat diubah yaitu obesitas, kurang olahraga, konsumsi garam berlebihan, merokok, dan mengkonsumsi alkohol serta stres (Dedulla, 2015).

Begadang adalah keadaan dimana seseorang berjaga tidak tidur sampai larut malam. Manusia secara normal harus tidur minimal delapan jam sehari. Sedangkan untuk kasus begadang ini, jam tidurnya kurang dari enam jam. Pada orang yang memiliki waktu tidur yang lebih sedikit yaitu kurang dari enam jam seperti pada pekerja shift malam menunjukkan beberapa gangguan fisiologi tubuh terutama pada perubahan tekanan darah (Sholeh, 2012).

Pekerjaan shift malam dapat dikaitkan dengan kurangnya waktu tidur malam pada pekerja. Bila dibandingkan dengan pekerja shift lain, pekerja shift malam memiliki waktu tidur yang lebih sedikit, yaitu kurang dari 6 jam tiap malam (Pickering, 2006).
Pekerja shift malam juga menunjukan tekanan darah yang berubah pada malam hari, tidur malam yang kurang pulas, dan peningkatan tekanan darah serta pola ekskresi katekolamin pada siang hari juga terganggu (Pickering, 2006). Hal ini menunjukan bahwa kurangnya tidur pada pekerja shift malam mempengaruhi siklus istirahat dan aktifitas seseorang menjadi semakin singkat (Pickering, 2006).

Tidur yang kurang dapat membawa kepada perkembangan hipertensi yaitu dengan cara meningkatkan aktivitas simpatis, meningkatkan stresor fisik dan psikis, dan meningkatkan retensi garam (Gangwisch et al, 2006).

Menurut William Frishman M.D, professor bidang kedokteran dan epidemiologi pada Albert Einstein College of Medicine di New York City Pada pagi hari tekanan darah itu akan cenderung meningkat lagi sewaktu bagun tidur (Vitahealth, 2004). Riset menunjukan bahwa tekanan paling rendah pada malam hari setelah tidur (Ikawati, 2010).

Security di Perumahan J-city Medan Johor adalah satuan kelompok yang di bentuk untuk melakukan keamanan fisik (physicial security) dalam penyelenggaraan swakarsa di lingkungan kerjanya. Oleh sebab itu agar dapat bekerja efektif, Seorang security selain perlu perlengkapan kerja yang lengkap juga kondisi fisik yang sehat sehingga dapat melaksanakan tugas dengan efektif, Untuk menjaga keamanan lingkungan kerja security menjalankan shift malamnya.

Peneliti mencoba meneliti aspek kesehatan atau risiko kesehatan yang ditimbulkan akibat kerja shift malam pada Security Perumahan J-city Medan Johor. Hal ini penting untuk mencegah kurang maksimalnya Security dalam bekerja dan meminimalisir risiko kesehatan pekerjaan yang timbul di kemudian hari, seperti hipertensi. Mencermati hal tersebut, maka penulis merasa perlu untuk mengkaji lagi pengaruh kerja shift malam terhadap peningkatan tekanan darah sistolik dan diastolik setelah bekerja pada Security di Perumahan J-city Medan Johor.

Berdasarkan uraian yang telah dikemukakan pada latar belakang, maka penelitian ini bertujuan untuk menganalisa perbandingan 
tekanan darah sebelum dan sesudah begadang pada security di perumahan J-City Medan Johor.

\section{METODE PENELITIAN}

Penelitian ini dilakukan dengan metode penelitian analitik observasi dengan pendekatan cross sectional yang bertujuan untuk mengetahui perbandingan tekanan darah sebelum dan sesudah begadang pada security di perumahan J-City Medan Johor. Penelitian dilakukan di Perumahan J-city Medan Johor pada bulan Januari 2017. Populasinya adalah seluruh security di Perumahan J-city Medan Johor yang berjumlah 48 orang dengan sampel adalah seluruh populasi yang memenuhi kriteria inklusi dan tidak memenuhi kriteria eksklusi.

Kriteria Inklusi sampel adalah Security lakilaki yang bekerja shift malam di Perumahan Jcity Medan Johor dan bersedia menjadi responden. Sedangkan kriteria Ekslusi adalah Security yang menkonsumsi makanan minuman yang mempengaruhi sistem kardiovaskular seperti: kopi, seafood, daging pada saat penelitian; Security yang sedang mengkonsumsi zat-zat perangsang, pelemas otot seperti diazepam, dan obat-obatan yang dapat memberi stimulan terhadap kerja jantung seperti obat penambah stamina pada saat penelitian (Pencalang, 2015) dan yang bekerja setiap malam (rotasi cepat). Teknik pengambilan sampel pada penelitian ini dilakukan secara total sampling atau seluruh populasi.

Instrumen penelitian adalah alat-alat yang digunakan untuk pengumpulan data. Instrumen yang digunakan pada penelitian ini diantaranya adalah spygmomanometer, stetoskop, dan lembar formulir persetujuan ikut penelitian, dan formulir-formulir lain yang berkaitan dengan pencatatan data. Data penelitian ini diperoleh melalui pengukuran langsung tekanan darah arteri brachialis dengan menggunakan alat spygmomanometer air raksa terhadap Security yang bekerja shift malam di Perumahan J-City Medan Johor.

Adapun prosedur percobaan yang dilakukan melalui tiga tahap, yaitu: responden diperiksa terlebih dahulu tekanan darahnya pada saat tidak bekerja; responden diminta istirahat selama 15 menit sebelum pengukuran tekanan darah dilakukan, dan responden diperiksa tekanan darahnya pada saat begadang untuk mengetahui perubahan tekanan darah sistolik dan diastoliknya.

\section{Analisis Data}

Data dianalisis untuk mengetahui distribusi frekuensi dan presentasi tiap variabel yang akan diteliti yaitu begadang dengan pengaruh perubahan tekanan darah sistolik dan diastolic kemudian dilanjutkan dengan uji statistik menggunakan uji $T$ Paired jika data terdistribusi normal, dan menggunakan uji wilcoxon jika data tidak terdistribusi normal. Untuk menguji normalitas data digunakan kolmogorov smirnov danShapiro wilk.

\section{HASIL PENELITIAN}

Total responden yang diperoleh awalnya berjumlah 48 responden, namun karena sebanyak 5 responden masuk kedalam kriteria ekslusi sehingga total responden menjadi 43 responden. Adapun beberapa kriteria ekslusi dalam penelitian ini adalah security yang mengkonsumsi makanan dan minuman yang mempengaruhi sistem kardiovaskular seperti: kopi, seafood, alkohol dan daging pada saat penelitian.

Ada dua faktor yang menjadi pengamatan penelitian ini, yaitu faktor hipertensi yaitu faktor risiko yang dapat diubah dan faktor risiko yang tidak dapat diubah. Faktor yang tidak dapat diubah terdiri dari genetika, umur, jenis kelamin, sedangkan faktor yang dapat diubah yaitu obesitas, kurang olahraga, komsumsi garam berlebihan, merokok dan mengkonsomsi alkohol serta stress (Dedulla, 2015).

Tabel 1. Distribusi Responden Berdasarkan Usia di Perumahan J-CityMedan Johor

\begin{tabular}{ccc}
\hline Usia & Frekuensi & Persentase (\%) \\
\hline Remaja 17- & 19 & $44,2 \%$ \\
25 & & \\
Dewasa $26-$ & 20 & $46,5 \%$ \\
45 & 4 & $9,3 \%$ \\
Lansia 46 - 55 & 43 & $100,00 \%$ \\
\hline Total & 43
\end{tabular}

Berdasarkan Tabel 1 dapat dilihat bahwa distribusi frekuensi responden berdasarkan usia 
yaitu dari 43 responden, terdapat jumlah responden kelompok usia 17-25 tahun sebanyak 19 responden (44,2\%), 26-45 tahun sebanyak 20 responden (46,5\%) dan 46-55 tahun sebanyak 4 responden $(9,3 \%)$.

Tabel 2. Distribusi Responden Berdasarkan Perubahan Tekanan Darah di Perumahan J-City Medan Johor

\begin{tabular}{ccc}
\hline $\begin{array}{c}\text { Perubahan } \\
\text { Tekanan }\end{array}$ & Frekuensi & $\begin{array}{c}\text { Persentase } \\
(\%)\end{array}$ \\
\hline Tetap & 3 & $7 \%$ \\
Meningkat & 32 & $74,4 \%$ \\
Menurun & 8 & $18,6 \%$ \\
\hline Total & 43 & $100,00 \%$ \\
\hline
\end{tabular}

Berdasarkan Tabel 2 persentase perubahan tekanan darah pada saat begadang didapat tekanan darah tetap sebanyak 3 responden (7\%) , tekanan darah meningkat sebanyak 32 responden $(74,4 \%)$ dan tekanan darah menurun sebanyak 8 responden $(18,6 \%)$.

Tabel 3. Distribusi Frekuensi Sistol di Perumahan J-City Medan Johor Medan

\begin{tabular}{ccc}
\hline $\begin{array}{c}\text { Perubahan } \\
\text { Tekanan }\end{array}$ & Frekuensi & $\begin{array}{c}\text { Persentase } \\
(\%)\end{array}$ \\
\hline-20 & 2 & $4,7 \%$ \\
-10 & 4 & $9,3 \%$ \\
0 & 8 & $18,6 \%$ \\
10 & 17 & $39,5 \%$ \\
20 & 11 & $25,6 \%$ \\
40 & 1 & $2,3 \%$ \\
\hline Total & 43 & $100,00 \%$ \\
\hline
\end{tabular}

Tabel 3 didapat frekuensi sistol terbanyak adalah pada kenaikan $10 \mathrm{mmHg}$ yaitu sebanyak 17 responden (39,5\%) kemudian diikuti oleh kenaikan $20 \mathrm{mmHg}$ sebanyak 11 responden $(25,6 \%)$, sistol yang tidak mengalami kenaikan maupun penurunan 8 responden $(18,6 \%), 4$ $(9,3 \%)$ yang mengalami penurunan $10 \mathrm{mmHg}, 2$ responden $(4,7 \%)$ mengalami penurunan 20 $\mathrm{mmHg}$ dan mengalami kenaikan sistol $40 \mathrm{mmHg}$ sebanyak 1 responden $(2,3 \%)$.

Tabel 4. Distribusi Frekuensi Diastol di Perumahan J-City Medan Johor

Perubahan Frekuensi Persentase

\begin{tabular}{ccc}
\hline Tekanan & & $(\%)$ \\
\hline-20 & 1 & $2,3 \%$ \\
-10 & 3 & $7 \%$ \\
0 & 10 & $23 \%$ \\
10 & 19 & $44,2 \%$ \\
20 & 9 & $20,9 \%$ \\
30 & 1 & $2,3 \%$ \\
\hline Total & 43 & $100,00 \%$ \\
\hline Berdasarkan tabel & 4 & didapat perubahan
\end{tabular}
diastol yang mengalami frekuensi terbanyak 19 responden $(44,2 \%)$ dengan kenaikan $10 \mathrm{mmHg}$, 9 responden $(20,9 \%)$ dengan kenaikan diastol 20 $\mathrm{mmHg}, 10$ responden (23\%) yang tidak mengalami perubahan kenaikan maupun penurunan diastol, 1 responden (2,3\%) mengalami kenaikan $30 \mathrm{mmHg}, 1$ responden $(2,3 \%)$ orang mengalami penurunan diastol 20 $\mathrm{mmHg}, 3$ responden (7\%) mengalami penurunan $10 \mathrm{mmHg}$.

Tabel 5. Ringkasan Hasil Uji T

\begin{tabular}{ccc}
\hline & Mean & Signifikasi \\
\hline Sistol Sebelum - & $-8,140$ & 0,001 \\
$\begin{array}{c}\text { Sistol Sesudah } \\
\text { Diastol Sebelum - } \\
\text { Diastol Sesudah }\end{array}$ & $-6,744$ & 0,001 \\
\hline
\end{tabular}

Berdasarkan Tabel 4.4 didapatkan rata rata sistol sebelum dan sesudah yaitu $-8,140$. Hasil penelitian ini berhubungan dengan signifikasi nilai $\mathrm{p}$ adalah 0,001 . Untuk rata-rata diastol sebelum dan sesudah didapatkan $-6,744$ yang juga berhubungan dengan signifikasi nilai $p$ adalah 0,001 .

\section{PEMBAHASAN}

Hasil penelitian berdasarkan tabel 1 bahwa distribusi frekuensi responden berdasarkan usia yaitu 43 responden terdapat jumlah responden kelompok usia 17-25 tahun sebanyak 19 responden $(44,2 \%), 26-45$ tahun sebanyak 20 responden (46,5\%) dan 46-55 tahun sebanyak 4 responden $(9,3 \%)$. Dalam hal ini usia merupakan salah satu faktor hipertensi. Hipertensi merupakan gejala yang paling sering ditemui pada orang lanjut usia dan menjadi faktor risiko utama insiden penyakit kardiovaskular (Kemsos dalam Setiyorini, 2014).

Berdasarkan tabel 2 persentase perubahan tekanan darah pada saat begadang didapat 
tekanan darah tetap sebanyak 3 responden $(7 \%)$, tekanan darah meningkat sebanyak 32 responden $(74,4 \%)$ dan tekanan darah menurun sebanyak 8 responden $(18,6 \%)$. Pada orang memiliki waktu tidur yang lebih sedikit yaitu kurang dari 6 jam seperti pada pekerja shift malam menunjukkan beberapa gangguan fisiologis tubuh terutama pada perubahan tekanan darah (Sholeh dalam Pencalang, 2015).

Tekanan darah tinggi merupakan penyakit multifaktoral yang dipengaruhi oleh berbagai faktor yaitu faktor individu seperti umur, jenis kelamin, faktor genetik serta faktor lingkungan seperti obesitas, stress, kualitas tidur, asupan garam, alkohol dan lain-lain (Kaplan dalam Setiyorini, 2014).

Berdasarkan tabel 3 didapat frekuensi kenaikan sistol $40 \mathrm{mmHg}$ sebanyak 1 responden $(2,3 \%)$ dan kenaikan terendah $10 \mathrm{mmHg}$ sebanyak 17 responden (39,5\%). Selanjutnya tabel 4 mengenai perubahan diastolik yang mengalami frekuensi terbanyak 19 responden $(44,2 \%)$ dengan kenaikan $10 \mathrm{mmHg}$ dan frekuensi terendah 1 responden (2,3\%) pada kenaikan diastol $30 \mathrm{mmHg}$ dan penurunan -20 mmHg sebanyak 1 responden (2,3\%).

Hasil penelitian ini sejalan dengan penelitian Indah (2009) menunjukkan bahwa tekanan ratarata sistolik adalah $136 \mathrm{mmHg}$ dan rata-rata tekanan darah diastolik adalah $87,78 \mathrm{mmHg}$. Ada perbedaan signifikan pada tekanan darah sistolik menurut umur $(p=0,002)$, jenis kelamin $(p=$ $0,011)$, pekerjaan $(p=0,012)$, genetik $(p=$ $0,003)$, obesitas $(p=0,004)$, kebiasaan olahraga $(\mathrm{p}=0,003)$, dan kebiasaan merokok ( $\mathrm{p}=$ 0,001 ). Dan ada perbedaan yang signifikan pada tekanan darah diastolik menurut jenis kelamin ( $p$ $=0,006)$, pekerjaan $(p=0,004)$, genetik $(p=$ $0,031)$, obesitas $(p=0,007)$, kebiasaan olahraga $(p=0,001)$, dan kebiasaan merokok $(0,002)$.

Dari hasil penelitian yang telah dilaksanakan pada security di Perumahan J-City Medan Johor diperoleh data dengan cara mengukur tekanan darah security sebelum dan sesudah begadang didapatkan tekanan darah mengalami peningkatan dan penurunan bahkan ada yang tidak mengalami perubahan. Hal ini berkaitan dengan mekanisme kerja hormonal yang mempengaruhi aktivitas jantung sehingga berdampak terhadap tekanan darah.

Penelitian ini sejalan dengan penelitian yang dilakukan Asmarita (2014) tentang Hubungan antara kualitas tidur dengan tekanan darah di RSU Karanganyar pada bulan Desember 2013 hingga Januari 2014. Menunjukkan adanya hubungan antara kualitas tidur dengan tekanan darah pada hipertensi dengan nilai $p=0,001$.

Demikian juga dengan penelitian Annisa (2013) yang menyatakan terdapat hubungan antara kualitas tidur dengan hipertensi dengan nilai $p=0,003$. Hal ini juga sejalan dengan penelitian Setiyorini (2014) yang hasilnya terdapat korelasi antara kualitas tidur dengan tekanan darah dengan $r$ hitung sebesar 0,843 dan $p$ value sebesar 0,00 yang artinya $p$ value kurang dari 0,05 sehingga $\mathrm{Ho}$ ditolak dan $\mathrm{Ha}$ diterima artinya terdapat hubungan antara kualitas tidur dengan tekanan darah.

Perubahan tekanan darah akibat begadang ini disebabkan oleh kadar hormon kortisol dalam darah yang juga dikenal sebagai hormon stress. Dalam keadaan normal, kadar hormon ini paling tinggi dideteksi didalam darah terutama pada pagi hari satu jam sebelum matahari terbit yaitu sekitar $20 \mu \mathrm{g} / \mathrm{ml}$ dan paling rendah sebesar 5 $\mu \mathrm{g} / \mathrm{ml}$ terutama pada pertengahan malam. Efek sekresi kortisol ini dihasilkan oleh perubahan siklus sinyal dari hipotalamus selama 24 jam. Bila seseorang merubah kebiasaan siklus tidurnya setiap hari maka perubahan pada siklus normal sekresi dari hormon kortisol juga akan berubah (Guyton, 2012).

\section{KESIMPULAN}

Dari hasil penelitian ini didapat frekuensi sistol terbanyak adalah pada kenaikan $10 \mathrm{mmHg}$ sebanyak 17 responden $(39,5 \%)$ dan terendah yaitu kenaikan $40 \mathrm{mmHg}$ sebanyak 1 responden $(2,3 \%)$. Sedangkan tekanan darah diastol terbanyak yang mengalami kenaikan $10 \mathrm{mmHg}$ sebanyak 19 responden $(44,2 \%)$ dan terendah yaitu pada kenaikan $30 \mathrm{mmHg}$ sebanyak 1 responden $(2,3 \%)$ dan pada penurunan -20 mmHg sebanyak 1 responden (2,3\%).

Berdasarkan hasil dan pembahasan penelitian tentang perbandingan tekanan darah sebelum dan sesudah begadang pada security di 
perumahan J-City Medan Johor yang dilaksanakan pada bulan September 2016 Februari 2017, diperoleh hasil bahwa adanya perubahan tekanan darah pada saat begadang dengan nilai $p=0,001$.

\section{Saran}

1. Disarankan untuk security agar dapat menjaga dan mengatur pola tidur yang baik setelah begadang sehingga dapat mempertahankan homeostasis yang baik.

2. Diharapkan kepada masyarakat yang membaca mampu mengatur jadwal tidur yang baik sehingga tekanan darah tidak berubah akibat kondisi seseorang yang kurang tidur.

3. Agar dapat melanjutkan dan mengembangkan penelitian sebelumnya sehingga dapat diketahui faktor- faktor lain yang berhubungan dengan perubahan tekanan darah yang disebabkan oleh begadang. Disarankan kepada peneliti selanjutnya untuk melakukan penelitian tentang perbandingan tekanan darah sebelum dan sesudah begadang berdasarkan shift kerja rotasi cepat dan shift kerja rotasi lambat.

\section{DAFTAR PUSTAKA}

Asmarita, I., 2014. Hubungan Antara Kualitas Tidur Dengan Tekanan Darah Pada Pasien Hipertensi di Rumah Sakit Umum Daerah Karanganyar. Fakultas Kedokteran Universitas Muhammadiyah: Surakarta.

Departemen Kesehatan Republik Indonesia, 2012. Masalah Hipertensi di Indonesia.

Dedullah, R. F., Malonda, et al. 2015. Hubungan Antara Faktor Risiko Hipertensi Dengan Kejadian Hipertensi Pada Masyarakat di Kelurahan Motoboi Kecil Kecamatan KotaMobagu Selatan Kota Mobagu:Fakultas Kesehatan Masyarakat Universitas Sam Ratulangi.

Gangwisch, et al. 2006. Short Sleep Duration as a Risk Factor for Hypertension. Analysesof the first Nasional health and Nutrition Examintion Survey.] Hypertension:47;833.
Ganong, W.F., 2005. Buku Ajar Fisiologi Kedokteran. Penerbit EGC. Jakarta: Hal $375-376$

Guyton, H., 2006.Buku Ajar Fisiologi Kedoteran. EGC. Jakarta. Hal 111 - 115

Ikawati, S., 2010.Cerdas Menggenali Obat. Penerbit Kanisilum. Jogjakarta: Hal 11

Indah, R.F., 2009. Perbedaan Tekanan Darah Sistolik dan Diastolik Menurut Karakteristik Demografi, Genetik, Obesitas, Kebiasaan Olahraga, dan Kebiasaan Merokok. Fakultas Kedokteran Airlangga. Surabaya: Universitas Airlangga.

Japardi, I., 2002. Gangguan Tidur. Usu digital library. tufts U. 19 Maret 2011. http://repository.usu.ac.id/bitstream/123 456789/1948/1/bedahiskandar\%20japardi12.pdf hal 203

Kitamura, T., 2002. Circadian rhythm of blood pressure is transformed from a dipper to a non-dipper pattern in shift workers with hypertension. Journal of Human Hypertension

Lim, H., 2013. Farmakologi Kardiovaskular Mekanisme \& Aplikasi Klinis.Jakarta.SOFMEDIA: Hal 2

Mardjono, M. 2009. Kesadaran dan Fungsi Luhur Neurologi Klinis Dasar. Dian Rakyat. Jakarta. Hal 187 - 189

Markov. D, 2013. Normal Sleep and Circardian Rhythms: Neurobiologic Mechanism Underlying Sleep and Wakefulness. Available from: http://jdc.jefferson.edu

Mauritz, L.S., Imam, et al. 2008. Faktor dan Penjadwalan Shift Kerja. Teknoin, Volume 13, Nomor 2, Desember 2008, 11-22 ISSN: 0853-869. tufts U. 19 Maret 2011

Notoatmodjo, S. 2010. Metodologi penelitian kesehatan. Jakarta: Rineka Cipta

Pencalang,M.A.,2015.Gambaran Perubahan Tekanan Darah Sistol dan Diastol pada Security yang Bekerja Shift Malam di Perumahan Taman Setia Budi Indah 1 dan Perumahan Bukit Johor Mas Medan Tahun 2015.Skripsi S-1 Fakultas Kedokteran Islam Sumatera Utara. Medan: Universitas Islam Sumatera Utara

Pickering, T.G., 2006. Could Hypertension Be a Consequence of the 24/7 Society? The Effects of Sleep Deprivation and Shift Work.The Journal Of Clinical Hipertension Volume 8, Issue 11: 819-822.

Poerwopoespito., et al.2010.Menggugah Mentalitas Professional dan Pengusaha 
Indonesia. Penerbit Grasindo. Jakarta: Hal 272

Riggio, E., et al. 2006. Health and shiftworking in an administrative environment.Journal of ManagerialPsychology: Hal 131 - 144

Sastroasmoro, S. 2014. Dasar-dasar Metodologi Penelitian Klinis edisi ke 5. Jakarta: CV. Sagung Seto

Setiyorini, Y., 2014. Hubungan Kualitas Tidur Dengan Tekanan Darah Pada Lansia Hipertensi Di Gamping Sleman Yogyakarta. Progran Studi IImu Keperawatan Sekolah Tinggi IImu Kesehatan. Yogyakarta: Aisyiyah.
Sherwood., L.2012. Fisiologi Manusia Dari Sel ke Sistem. Jakarta. EGC Hal 373;375

Sholeh, Moh2013.Terapi Shalat Tahajud.Tim konversi mizan digital publishing JakartaHal 154

Simanjuntak, M.A. 2014. Hubungan Antara Tekanan Darah Sistolik, Tekanan Darah Diastolik, Tekanan Nadi dan Tekanan Arteri Rata-rata Dengan Fungsi Kognitif pada Usia diatas Lima Puluh Tahun. Medan

World Health Organization, 2013. World Health Day - 7 April 2013. www.who.int. (10 Maret 2013) 